\title{
KINETICS OF INDIVIDUAL POLYCHLORINATED BIPHENYL (PCB) COMPONENTS IN JUVENILE SOLE (SOLEA SOLEA) IN RELATION TO THEIR CONCENTRATIONS IN FOOD AND TO LIPID METABOLISM
}

\author{
J. P. Boon,* R. C. H. M. Oudejans† and J. C. Duinker
}

*Netherlands Institute for Sea Research, P.O. Box 59, 1790 AB Den Burg, Texel, The Netherlands. Telephone: 02226-541, †Laboratory of Chemical Animal Physiology, State University of Utrecht, Padualaan 8, 3508 TB Utrecht, The Netherlands and †Institute für Meereskunde an der Universität Kiel, Düsternbrookerweg 20, $2300 \mathrm{Kiel}$, FRG

(Received 16 February 1984)

\begin{abstract}
PCBs were administered to juvenile soles (Solea solea) with food. Homogenates of gut, liver, brain, dark skin, muscle and gills were analysed for their contents of individual PCB components. The relative contributions of individual components to total PCB were virtually indentical in the various organs sampled at the same day in a 275 -day period.

2. During the experiment concentrations on a (pentane-extractable) lipid basis of most PCB components declined in all organs regardless of lipid metabolism. The results suggest that $\mathrm{PCB}$ patterns in organs are determined by equilibrium partitioning. So components remained mobilizable from organs whose lipid contents increased. This is in contrast with the idea that PCBs are taken up and stored in lipids under circumstances of increasing lipid content in organs.

3. The plateau-values of the steady-states of lipid based concentrations of PCB components decreased in all organs. This might have been due to changes in lipid contents or lipid composition in some organs.
\end{abstract}

\section{INTRODUCTION}

Polychlorinated biphenyls are highly lipophilic (Tulp and Hutzinger, 1978; Bruggeman et al., 1982) and environmentally persistent chemicals with many industrial applications. Fish can accumulate PCBs from water (Hansen et al., 1974; Guiney et al., 1977, Bruggeman et al., 1981) and from their diet (Guiney and Peterson, 1980; Bruggeman et al., 1981; Pizza and O'Connor, 1983; Boon, 1984). Autoradiography studies with carp (Yoshida et al., 1973) and flounder (Solbakken J. E., personal communication) showed highest concentrations of PCBs in lipid-rich parts of the fish and in the gall-bladder.

Structural features cause different elimination rates between individual components in fish, resulting in differences in $\mathrm{PCB}$ composition between tissues and the source of uptake (Hansen et al., 1974; Bruggeman et al., 1981; Boon 1984).

In the laboratory study discussed in this paper, known amounts of food were offered to juvenile (one-year-old) soles. Juveniles were chosen because the development of sexual products can affect the behaviour of PCBs considerably (Guiney et al., 1979). Concentrations of individual PCB components were measured in several organs and tissues of the soles and in the food. Lipid contents and lipid composition of the organs and tissues were determined in order to study their possible influence on the kinetics of uptake and elimination of PCBs.

\section{MATERIALS AND METHODS}

\section{Collection of the fish}

One-year-old soles were captured in the Western Wadden
Sea in March 1982. Care was taken to avoid damage during capture: the ship towed the beam-trawl for at most $5 \mathrm{~min}$ and the net was opened, under water, in a $250 \mathrm{dm}^{3}$ tub on deck. The fish were transferred to $275 \mathrm{dm}^{3}$ all-glass tanks with coarse (containing less than $0.1 \%$ particulates $<63 \mu \mathrm{m}$ ) uncontaminated sediment at the bottom. They were treated with an antibiotic (Furanace; Dainippon Pharmaccutical $\mathrm{Co}$ ) to stop infection of small wounds resulting from capture. With these precautions, casualties within 2 weeks after capture were reduced to less than $10 \%$

\section{Experimental conditions}

Batches of $300 \mathrm{~m}^{3}$ water from the Western Wadden Sea were allowed to settle for at least 2 months before use in the experiment. Before entering an experimental tank the water was u.v. treated in order to kill algae, bacteria or viruses present to protect the system against algal growth and the fish against harmful micro-organisms.

The treated water was filtered twice $(10$ and $1 \mu \mathrm{m}$ pore size) to reduce the input of all kinds of suspended particulate matter (SPM) into the experimental tanks. SPM can adsorb PCB components from solution, thus decreasing dissolved concentrations. Moreover, algae are not killed very efficiently by u.v. treatement, so algae still living after treatment were removed by filtration.

The temperature during the experiment was not regulated during the first 105 days of the experinent and varied between $18.0-21.0^{\circ} \mathrm{C}$. From day 106 onwards, temperature was regulated at $18.7 \pm 0.5^{\circ} \mathrm{C}$. Salinities ranged from $28.8-31.0 \times 10^{-3}$ and water flow was maintained at 535 $\mathrm{cm}^{3} \cdot \min ^{-3}$.

These values for temperature and salinity permitted good conditions for growth of the soles (Fonds, 1975). From day 75 onwards, the fish were fed every other day with a known amount of a diet containing $90 \%$ sole dry food (Trouw BV, Deventer, The Netherlands) mixed with $10 \%$ yeast (Verenigde Nederlandse Reform). 


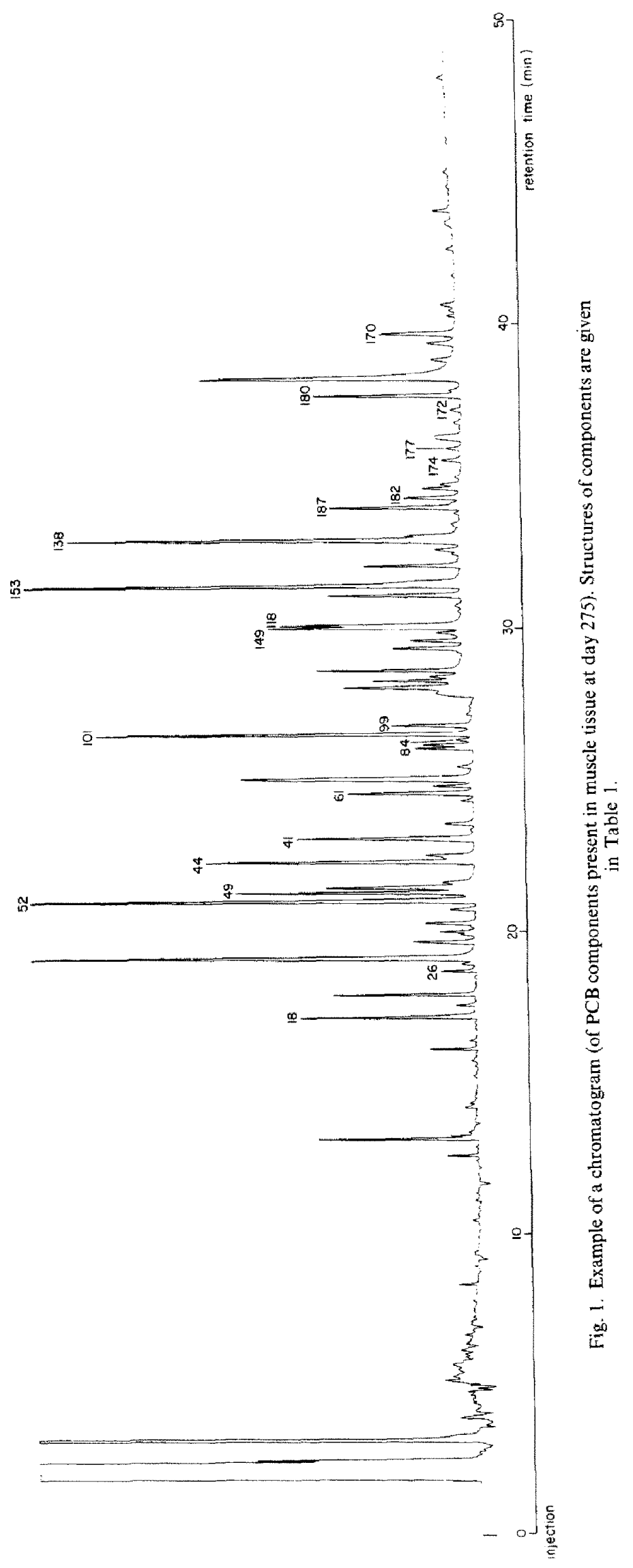




\section{Dissection of the fishes}

At day 1 (within 1 week after capture), at day 75 and at day 275 respectively, 22, 10 and 8 fishes were anacsthetized with MS 222 (Sandoz), weighed and frozen at $-25^{\circ} \mathrm{C}$. The fish of days 75 and 275 were also used as a reference group in a study on the kinetics of individual components present in the technical PCB mixture Clophen A40 (Boon, 1984). Sampling was done at least $36 \mathrm{hr}$ after the last feeding to ensure empty intestines. Dissection was performed within 2 weeks after death.

The following precautions were taken to avoid contamination of the samples. All glassware, the mortar and pestle were heated for $12 \mathrm{hr}$ at $350^{\circ} \mathrm{C}$ and cleaned with hexane before use. Metal tools were rinsed with dichloromethane and hexane. All solvents used were of nanograde quality (Mallinckrodt).

Organs and tissues selected were liver, intestine (without oesophagus and stomach), dark skin, muscle tissue between dark skin and bones, gills, and brain plus cerebrospinal fluid.

\section{Determination of $P C B S$}

Up to $7 \mathrm{~g}$ of tissue was ground with anhydrous $\mathrm{Nid}_{2} \mathrm{SO}_{4}$ and soxhlet extracted with pentane for $8 \mathrm{hr}$. A detailed description of the methods used is given in Boon (1984).

Identification and quantification of samples was done with a synthetic standard mixture containing 85 individual PCB components, which could be separated into 81 peaks. This mixture was injected every 10th injection for recalibration of retention times and response factors of components. If the shift in retention time of any component present in the mixture was more than $0.05 \mathrm{~min}$ or when a response factor of a component changed more than $10 \%$ between two injections of the standard mixture, the intermediate nine samples were reanalysed.

\section{Analysis of lipid composition}

Tissue samples were extracted with chloroform/methanol according to the method of Bligh and Dyer (1959), or with pentane (Boon, 1984). The various lipids present were separated on TLC plates (Baker-Flex ${ }^{\text {Bi }}$ Silica-Gel IB2) according to Björkman et al. (1972). The relative contributions of lipid classes were determined by densitometry of the TLC plates as described by Oudejans and van der Sluis (1979).

\section{RESULTS}

Many peaks originating from PCB components were present in the chromatograms (an example is given in Fig. 1). Those which contained only one component according to Duinker and Hillebrand (1983) are discussed in this paper, since it is not relevant to study the behaviour of a peak that is made up of two or three components. The individual components are numbered according to the system given by Ballschmiter and Zell (1980). The structures of the components chosen are given in Table 1 . The PCBs present in the fish food were already present (in the commercial product) as a "natural" contamination.

\section{Relation between $P C B$ patterns in fish organs and food}

In the period between days 1 (within 1 week after capture in the Western Wadden Sea) and 75, no data on the food supply of the fish were collected; during this period the fish had to get used to life in an unnatural environment (the experimental tanks). The fish also had to learn to accept the dry food; to achieve this, portions of dry food were alternated with portions of minced mussels during the first 3 weeks. From this time onwards, the dry food was readily eaten.

During the second period of the experiment (days 75-275), four batches of dry food were given to the fish in known amounts. The food was eaten by the fish within $20 \mathrm{~min}$ after it had been offered. Despite variations in PCB concentrations (on a fresh weight basis) between batches, the composition of the PCB mixture in the batches (the PCB-pattern) was very constant (Fig. 2).

The PCB patterns in different organs of the group of fish sampled at a particular day were virtually identical, but between sampling days considerable differences were present. Examples of organs from fish of days 1, 75 and 275 are shown in Figs 3, 4 and 5.

At day 75 the relative contributions to total $\mathrm{PCB}$ of a tri- and some tetrachlorobiphenyls (18, 52, 49, 44,41 ) were lower than in the food used from day 75 until day 275 (compare Fig. 2 with Figs 3 and 4). At day 275 their contributions were higher in all organs and the PCB pattern in the organs resembled that of the food (Fig. 5). However, significant differences between food and fish organs were present in the relative contributions of many components. For a comparison of the PCB patterns in food and fish organs, the concentrations of all components have been expressed as a ratio of the concentration of a reference component. For this purpose component 44 was chosen, since it was present in all samples in medium concentrations (Figs 3-5); the choice is rather arbitrary however.

Table 2 shows higher concentration ratios in organs for components $52,41,61,101,99,118,153$, and 138 , and lower for components $18,26,84,149,177$ and 174. No significant differences were found for components $49,187,183,172,180$ and 170 .

\section{Relations between PCB concentrations in fish organs, growth and lipid content}

Growth of the fish during the experiment is given in Fig. 6; it was accompanied by a considerable rise in pentane-extractable lipid content in dark skin, gills, muscle and liver. The lipid contents of gut and brain remained rather similar (Fig. 7).

The lipid based concentrations of all PCB components except 18,26 and 84 declined during the experiment. This trend was observed in all organs and is also represented in Fig. 7 for some dominant

Table 1. Individual PCB components selected for this study. Numbering of components according to Ballschmiter and Zell (1980). The components are given in order of elution from the GLC

\begin{tabular}{clcc}
\multicolumn{4}{c}{ column } \\
\hline $\begin{array}{c}\text { Component } \\
\text { No. }\end{array}$ & $\begin{array}{c}\text { Chlorine } \\
\text { substitution }\end{array}$ & $\begin{array}{c}\text { Component } \\
\text { No. }\end{array}$ & $\begin{array}{c}\text { Chlorine } \\
\text { substitution }\end{array}$ \\
\hline 18 & $2,2^{\prime}, 5$ & 118 & $2,3^{\prime}, 4^{\prime}, 4^{\prime}, 5^{\prime}$ \\
26 & $2,3^{\prime}, 5$ & 153 & $2,2^{\prime}, 4^{\prime}, 4^{\prime}, 5^{\prime}, 5^{\prime}$ \\
52 & $2,2^{\prime}, 5,5^{\prime}$ & 105 & $2,3^{\prime}, 3^{\prime}, 4^{\prime}, 4^{\prime}$ \\
49 & $2,2^{\prime}, 4^{\prime}, 5^{\prime}$ & 138 & $2,2^{\prime}, 3,4^{\prime}, 4^{\prime}, 5^{\prime}$ \\
44 & $2,2^{\prime}, 3,5^{\prime}$ & 187 & $2,2^{\prime}, 3,4^{\prime}, 5,5^{\prime}, 6^{\prime}$ \\
41 & $2,2^{\prime}, 3,4$ & 183 & $2,2^{\prime}, 3,4,4^{\prime}, 5^{\prime}, 6$ \\
61 & $2,3,4,5$ & 174 & $2,2^{\prime}, 3,3^{\prime}, 4^{\prime}, 5,6^{\prime}$ \\
84 & $2,2^{\prime}, 3,3^{\prime}, 6$ & 177 & $2,2^{\prime}, 3,3^{\prime}, 4^{\prime}, 5,6$ \\
101 & $2,2^{\prime}, 4,5^{\prime}, 5^{\prime}$ & 172 & $2,2^{\prime}, 3,3^{\prime}, 4^{\prime}, 5,5^{\prime}$ \\
99 & $2,2^{\prime}, 4^{\prime}, 4^{\prime}, 5$ & 180 & $2,2^{\prime}, 3,4,4^{\prime}, 5,5^{\prime}$ \\
149 & $2,2^{\prime}, 3,4^{\prime}, 5^{\prime}, 6$ & 170 & $2,2^{\prime}, 3,3^{\prime}, 4^{\prime}, 4^{\prime}, 5$ \\
\hline
\end{tabular}




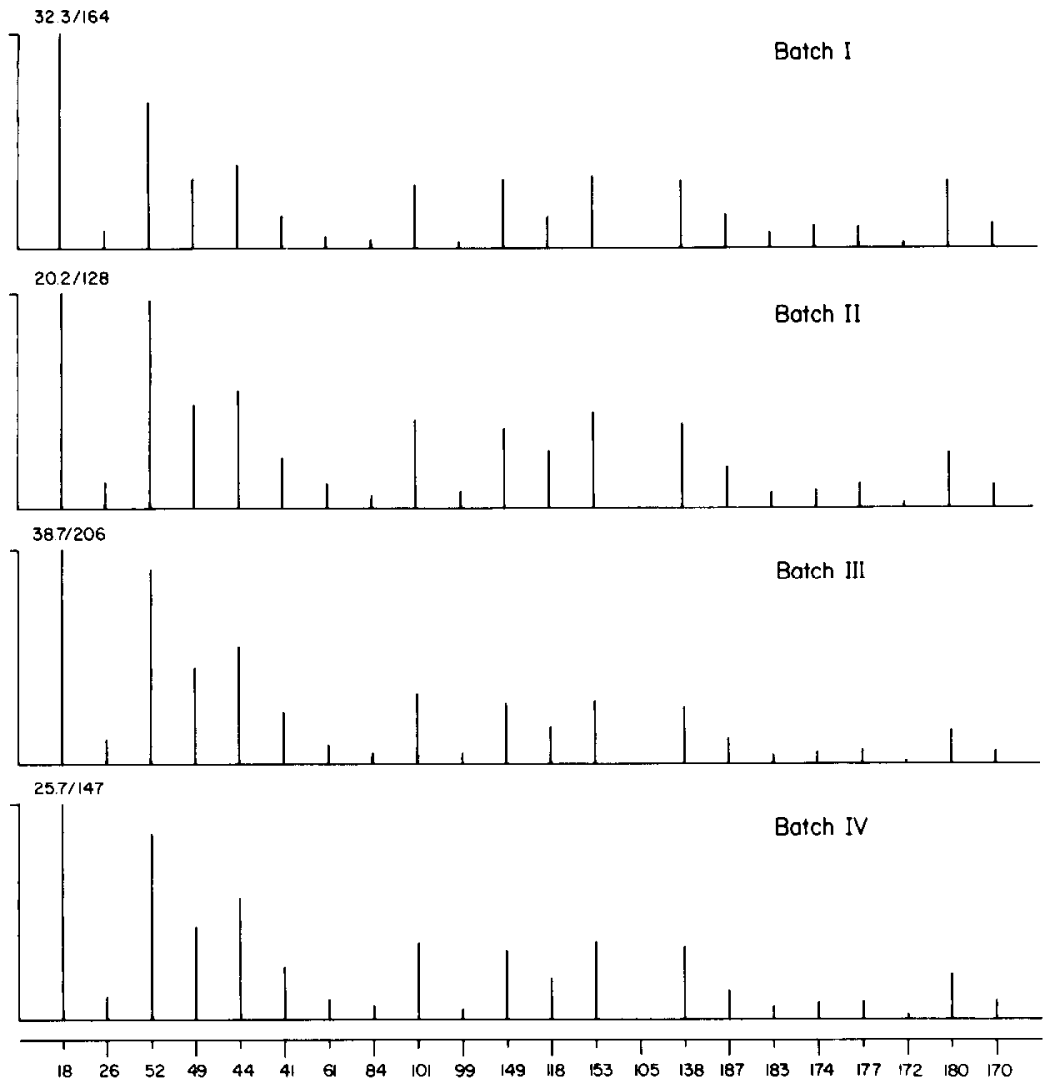

Fig. 2. Concentrations of PCB components in the four batches of fish food used in the period of days 75-275. The components are given in order of elution from the GLC column. The two numbers $a / b$ given in the upper left hand corner of cach histogram rcpresent: (a) the concentrations of the component with the highest concentration (the concentrations of components are proportional to height of bar); values in $\mathrm{ng} \cdot \mathrm{g}^{-1}$ fresh weight, (b) sum of concentrations of all components; values in $\mathrm{ng} \cdot \mathrm{g}^{-1}$ fresh weight.

components with various degrees of chlorination $(18$, $52,153,187$ and 180 ).

Lower concentrations of PCB components resulted partly from growth and lipid enrichment of the organs or tissues; the amounts of components still increased during the same period. However, Table 4 illustrates, for components $18,52,153,187$ and 180 , that the sums of the amounts present in all organs together were higher at day 1 than at day 75 , so a net elimination must have occurred during this period. In the second period of the experiment (days 75-275), the amounts of components 153, 187 and 180 decreased again, although to a lesser degree. A net uptake of these components occurred only in liver, an organ with a strong increase in lipid content (Table 3). Components 18 and 52 were present in higher amounts in all organs of day 275 .

However, the amounts of these two components given with the food were more than an order of magnitude higher than their increases in amounts in organs (Table 4).

Comparison between chloroform/methanol and pentane extracts of fish organs

The decrease in (lipid-based) PCB concentrations with increasing pentane-extractable lipid contents of some organs could be caused by differences in lipid composition. Therefore a comparison was made between tissue extraction with $n$-pentane (after drying with anhydrous $\mathrm{Na}_{2} \mathrm{SO}_{4}$ ), and the generally accepted method of total lipid extraction with chloroform/methanol (Bligh and Dyer, 1959). For this purpose the fish of day 275 were divided into two groups; one of which was extracted with chloroform/methanol, the other one with pentane $/ \mathrm{Na}_{2} \mathrm{SO}_{4}$. Table 5 shows that only the amounts of polar lipids (i.e. phospholipids and due to the method used also monoacylglycerols) were significantly different. Diacylglycerols, sterols, free fatty acids and triacylglycerols showed a high similarity. Thus, the extraction method used did extract all major lipid classes, but polar lipids probably not quantitatively. TLC images of different extracts of dark skin are shown in Fig. 8.

\section{Changes in the lipid composition of fish organs}

Relative contents of polar lipids (i.e. phospholipids plus monoacylglycerols) and several classes of neutral lipids (diacylglycerols, sterols, free fatty acids, triacylglycerols and-in liver-steryl esters) were determined in extracts of fish organs. The results are given in Fig. 9. After capture in March the fish were very lean compared with day 275 (Fig. 7); triacylglycerols 

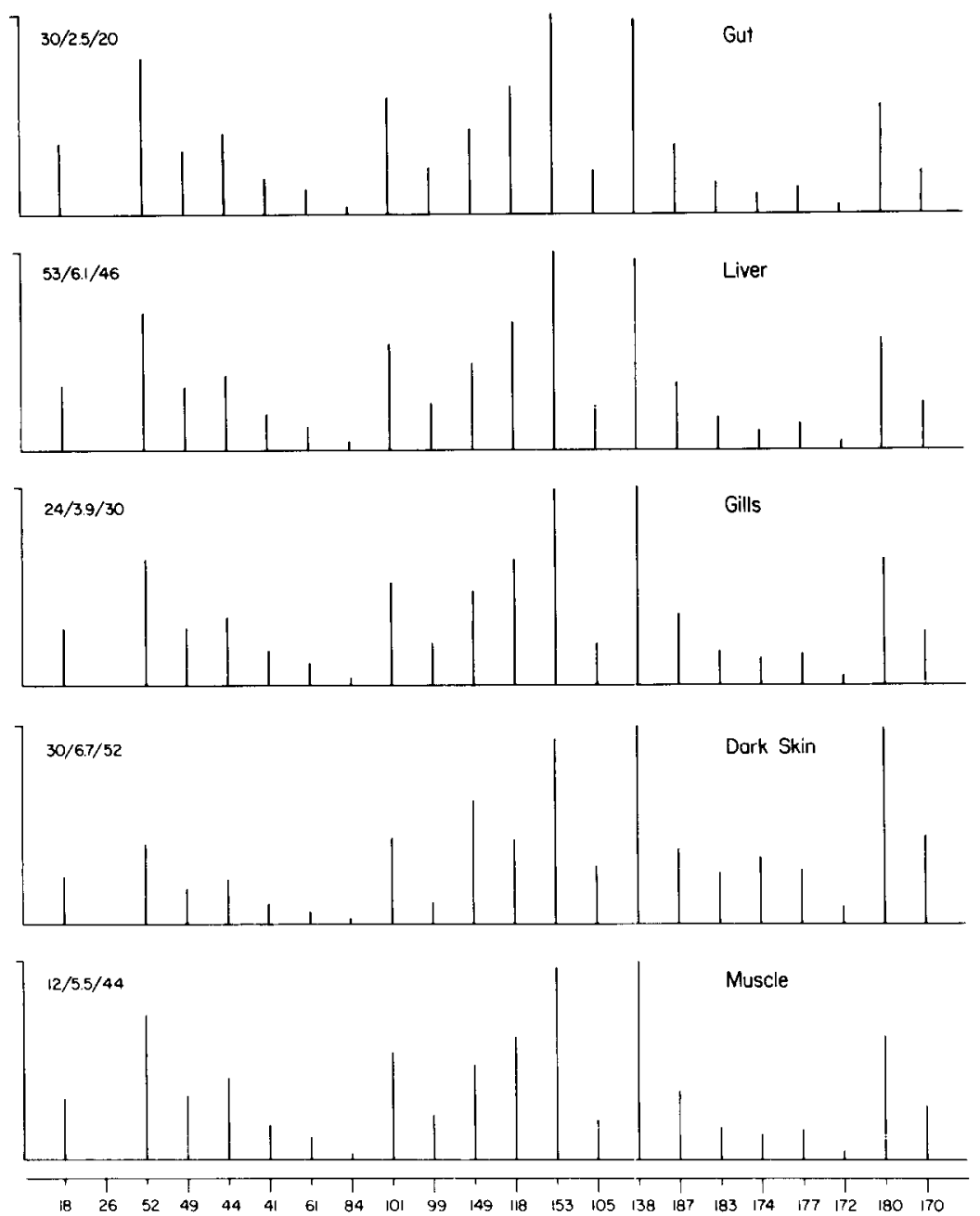

Fig. 3. Concentrations of PCB components in organs of juvenile Solea solea sampled at day 1. The concentrations of components are given in order of elution from the GLC column. The three numbers $a / b / c$ given in the upper left hand corner of each histogram, represent: (a) the concentration of the component with the highest concentration (concentrations of components are proportional to height of bar); values in $\mathrm{ng} \cdot \mathrm{g}^{-1}$ wet weight, (b) as in (a), with concentration expressed in $\mu \mathrm{g} \cdot \mathrm{g}^{-1}$ pentane-extractable

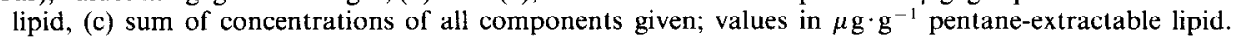

were almost absent. Exceptions were the gut and brain. The gut showed a very constant lipid composition during the entire experiment, lacking triacylglycerols.

The brain was not investigated at day 1 ; at day 75 the contribution of polar lipids was considerably lower than at day 275 and the contribution of free fatty acids was much higher (both samples were pentane extracts).

\section{DISCUSSION}

The PCB patterns changed very similarly for all fish organs during the experiment. From day 75 until 275 , the palterns got more similar to those of the food given during this period. However, they did not become identical. Differences between components in their degrees of bio-accumulation (resulting in the differences in PCB patterns between food and organs) can result from differences in uptake and elimination rates. The differences in bio-accumulation of different components considered in this study, are well correlated with differences in the biological half-times $\left(t_{1 / 2}\right)$ in another study with juvenile soles, where components $18,26,52,49,44,41,61,84,101,99$ and 118 were investigated (Boon, 1984). For these components it was shown that differences in elimination rates were responsible for differences in bioaccumulation.

All heptachlorobiphenyls investigated in this study are at least not bio-accumulated more strongly than component $44(187,183,172,180,170)$; some are accumulated even less $(177,174)$. Taking into account their high degree of chlorination, elimination is not likely to be the only cause for this behaviour. In a study with two bivalve species (Cerastoderma edule 

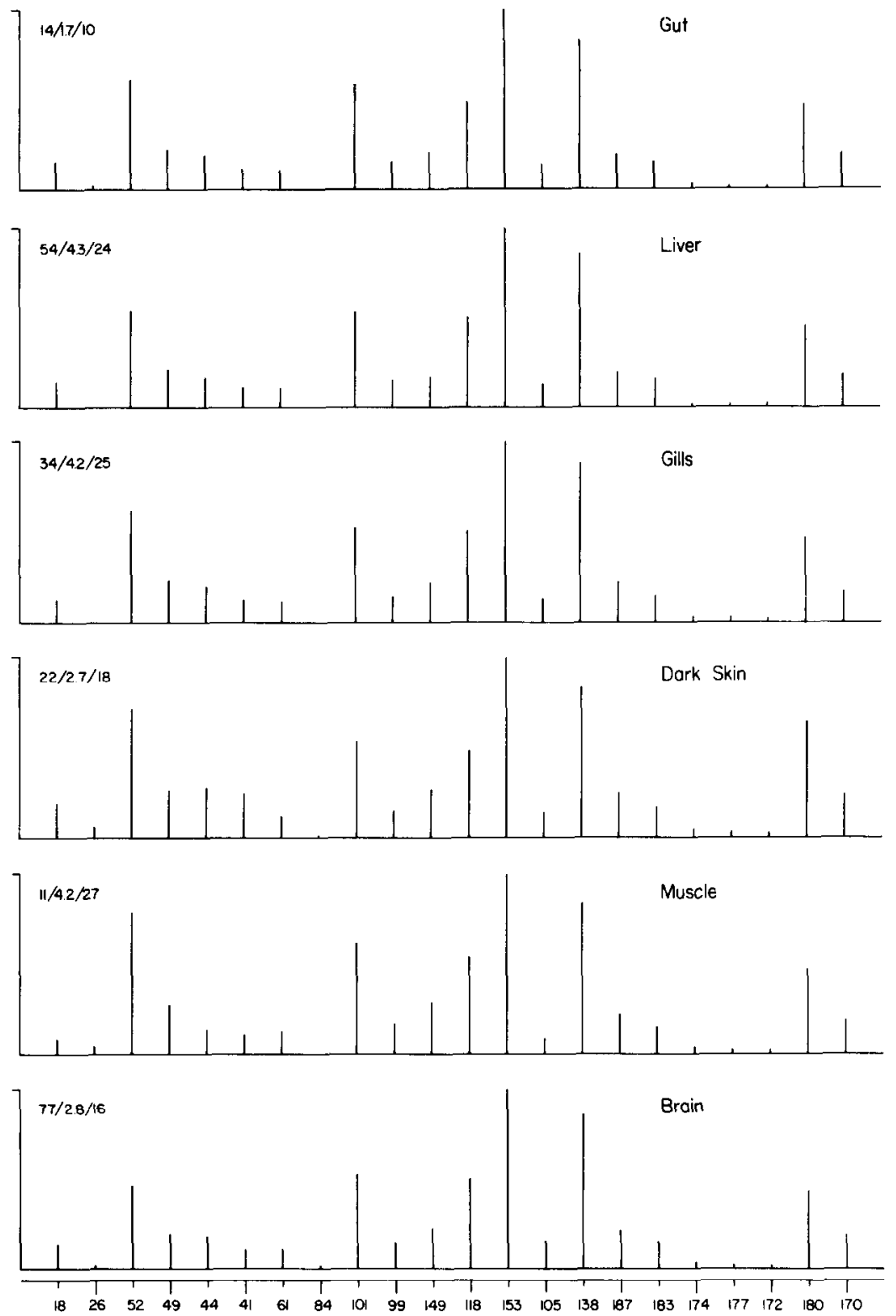

Fig. 4. Concentrations of PCB components in organs of juvenile Solea solea sampled at day 75. For explanation see Fig. 3. 

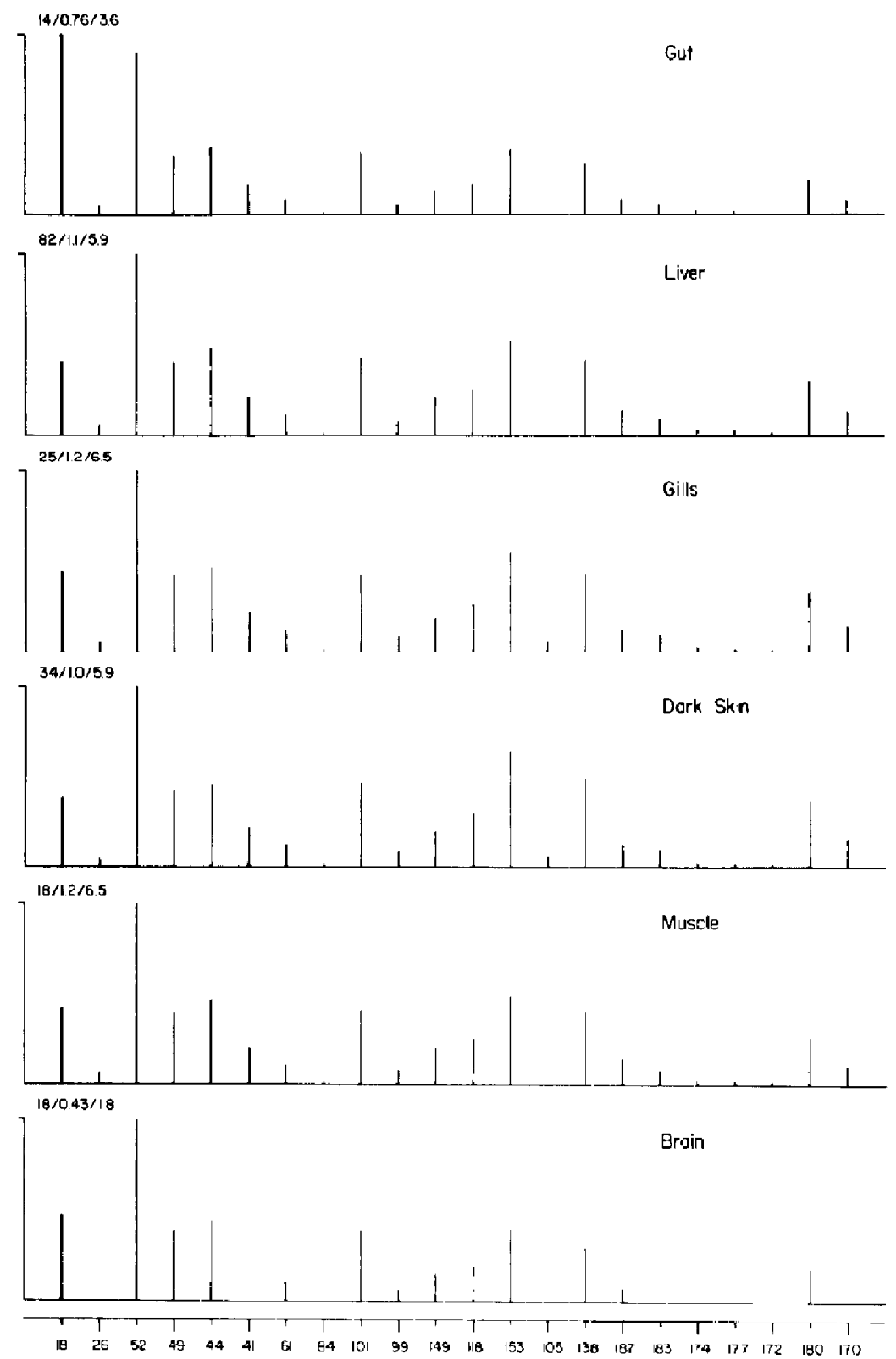

Fig. 5. Concentrations of PCB components in organs of juvenile Solea solea sampled at day 275. For explanation see Fig. 3 . 
Table 2. Biomagnification of individual PCB components in fish compared with food. $\bar{R}$ is the mean ratio of the concentrations of the component $x$ and concentration of component 44 in the four batches of food and in the fish organs. The significance levels for differences of $\bar{R}$ between food and fish organs were determined by one way analysis of variance

\begin{tabular}{|c|c|c|}
\hline \multirow[b]{2}{*}{ Component } & \multicolumn{2}{|c|}{$\ddot{R}$} \\
\hline & Fond & Organs \\
\hline 18 & 2.00 & $0.92^{* * * *}$ \\
\hline 26 & 0.22 & $0.13^{* * *}$ \\
\hline 52 & 1.69 & $2.20^{* * *}$ \\
\hline 49 & 0.83 & 0.88 \\
\hline 41 & 0.43 & $0.46^{\star}$ \\
\hline 61 & 0.18 & $0.26 * * *$ \\
\hline 84 & 0.11 & $0.047^{* * *}$ \\
\hline 101 & 0.69 & $0.93 * * *$ \\
\hline 99 & 0.11 & $0.17^{* *}$ \\
\hline 149 & 0.65 & $0.40^{* *}$ \\
\hline 118 & 0.39 & $0.54^{*}$ \\
\hline 153 & 0.71 & $1.10 * *$ \\
\hline 138 & 0.65 & $0.86^{*}$ \\
\hline 187 & 0.31 & 0.26 \\
\hline 183 & 0.13 & 0.19 \\
\hline 174 & 0.19 & $0.046^{* *}$ \\
\hline 177 & 0.17 & $0.062^{*}$ \\
\hline 172 & 0.048 & 0.036 \\
\hline 180 & 0.49 & 0.61 \\
\hline 170 & 0.20 & 0.29 \\
\hline
\end{tabular}

and Macoma balthica; Langston (1978)), the uptake of Aroclor 1260 (containing many hepta- and octachlorobiphenyls) was found to be lower than that of Aroclor 1254 (where penta- and hexachlorobiphenyls are dominant). Shaw and Connell (1982) observed similar differences between penta- and hexachlorobiphenyls and hepta- and octachlorobiphenyls in the polychaete worm Capitella capitata and the fish species Mugil cephalus. They attributed the lower uptake of hepta- and octachlorobiphenyls to their unfavourable stereochemistry. The PCB patterns in the organs of the same fish were very similar at each sampling day. The PCB concentrations on a lipid basis declined during the experiment (except for 18 , 26 and 84 ), both in organs with a relatively constant lipid content (gut and brain) and lipid composition (especially the gut) as well as in the organs with increasing contents of total lipid content and of triacylglycerols. This implies that in organs with a constant lipid content, elimination of components has occurred: but that in liver, an organ with a strong increase in lipid content, uptake had to occur despite the decrease in concentrations. Thus a redistribution of PCB components must have taken place between the organs according to exchange equilibria (Table 3). Table 4 shows that the amounts of PCB components administered with the food between days 75 and 275 were high enough to maintain the higher concentrations of day 75 during this period. Nevertheless concentrations decreased, so the plateau-value of the steady-state(s) of the lipid based concentrations of components must have decreased during this period. A reason for this might have been the changes in lipid content and composition (i.e. a strong increase in triacylglycerols) that occurred in muscle, dark skin, gills and liver. Since triacylglycerols were almost absent in organs of day 1, the same mechanism is likely to have been at least partly responsible for the decrease in PCB concentrations during the first period of the experiment (days 1-75), since the amounts of food given were, although unknown, large enough to increase fish weight (Fig. 5) and the amounts of triacylglycerols (typical depot lipids (Allen, 1976)) increased in dark skin, muscle and gills (Fig. 9).

Schneider (1982) found that differences in PCB concentrations on a lipid basis between cod fillets (muscle), gonads and liver could be correlated with the fraction of phospholipids of the total lipid extract. The higher the phospholipid fraction, the lower PCB concentrations on a (total) lipid basis in organs of the same fish. Our polar lipid fraction consisted of phospholipids and monoacylglycerols. In our samples of different organs of the same fish there was no significant correlation between the fraction of polar lipids and total PCB concentrations on a (pentaneextractable) lipid basis (Student's $t$-test after arcsine transformation of fractions). The highest PCB concentrations in all organs were present when the fractions of polar lipids were highest, i.e. at day 1. The concentrations on a neutral lipid basis $(=$ total lipids minus the fraction of polar lipids) were not constant during the experiment. So, the idea that PCBs do not have an affinity for polar lipids is not supported by our results.

Acknowledgements - The authors are very grateful to $\mathrm{H}$. J. Boekel for building the experimental setup. Dr M. Fonds gave valuable advice concerning capture, maintenance and feeding of the fish. I. van der Sluis is thanked for his skilful advice concerning the determination of the lipid composition of the fish organs. F. Eijgenraam developed a computer program which allowed a very convenient handling of the GC data and made it possible to plot concentrations of components. M. T. J. Hillebrand assisted with the gas chromatographical part and the design of the computer program.

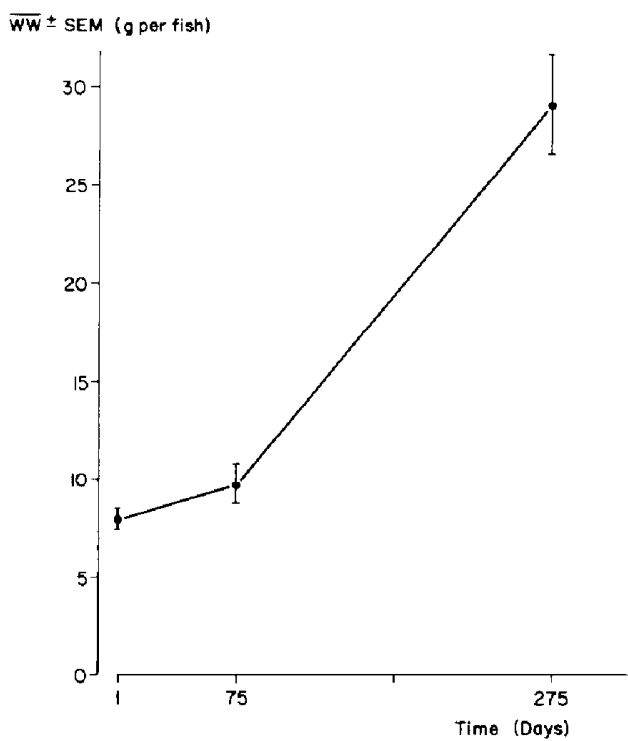

Fig. 6. Growth of juvenile Solea solea during the experiment represented by the increase in mean wet weight $W W$ per fish $\pm S E M$. 

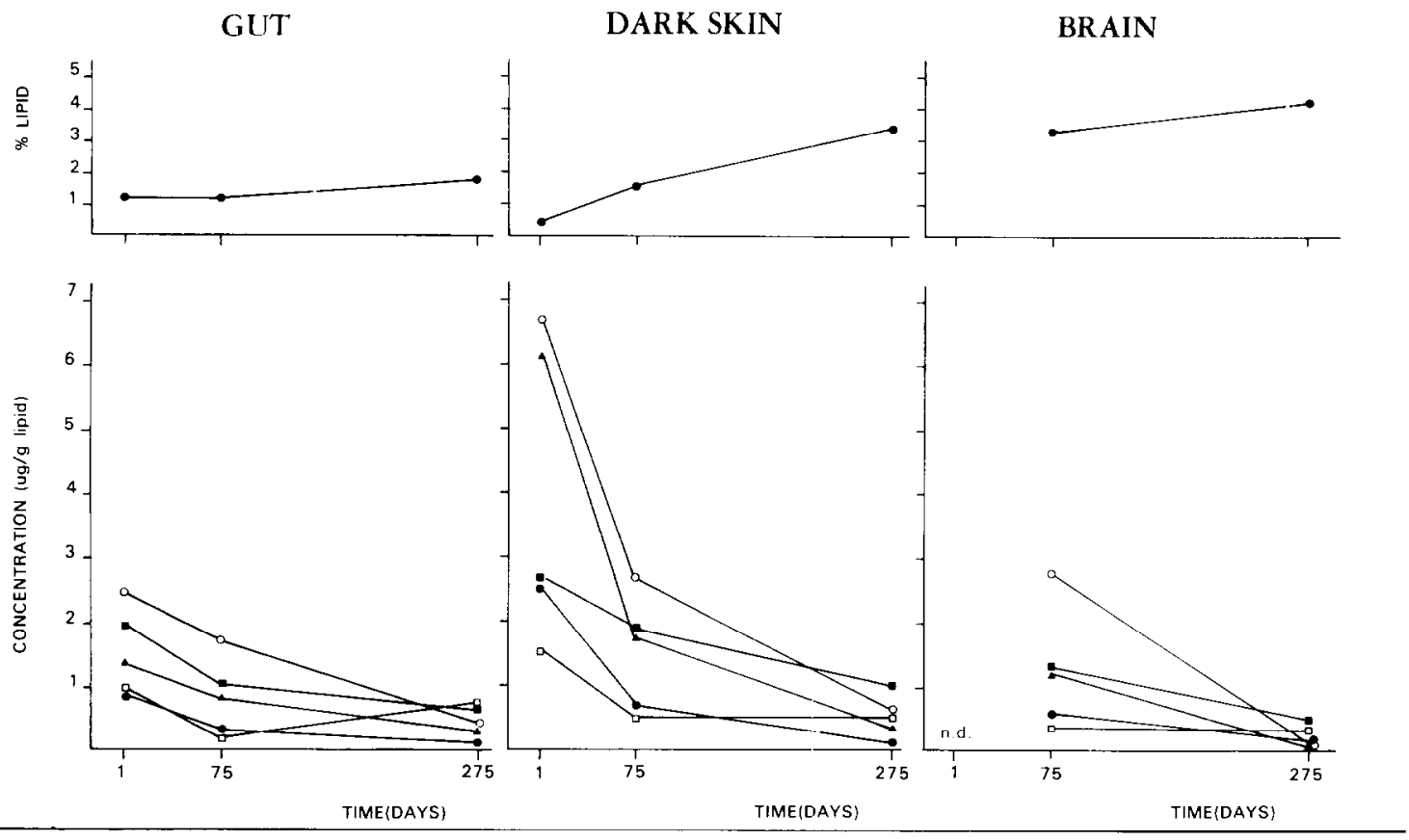

GILLS

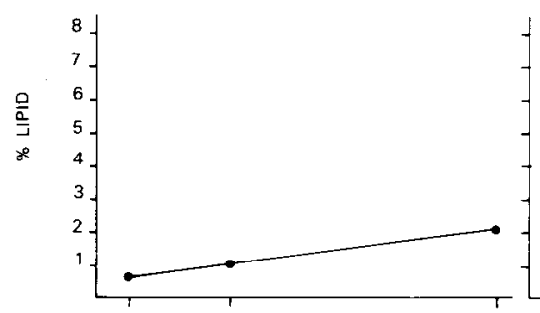

\section{LIVER}

MUSCLE
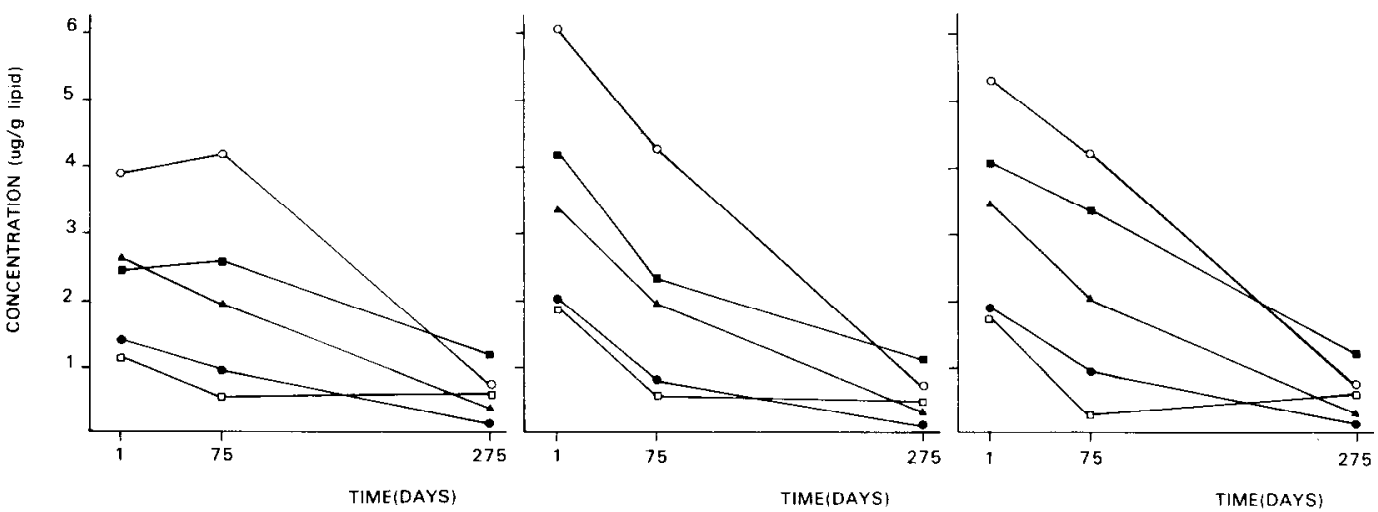

Fig. 7. Changes in concentrations of PCB components $18(\square), 52(\mathbf{\square}), 153(0), 187(\mathbf{O})$ and $180(\mathbf{A})$ on a (pentane-extractable) lipid basis in organs of juvenile Solea solea, together with changes in the (pentane-extractable) lipid contents of the organs. 

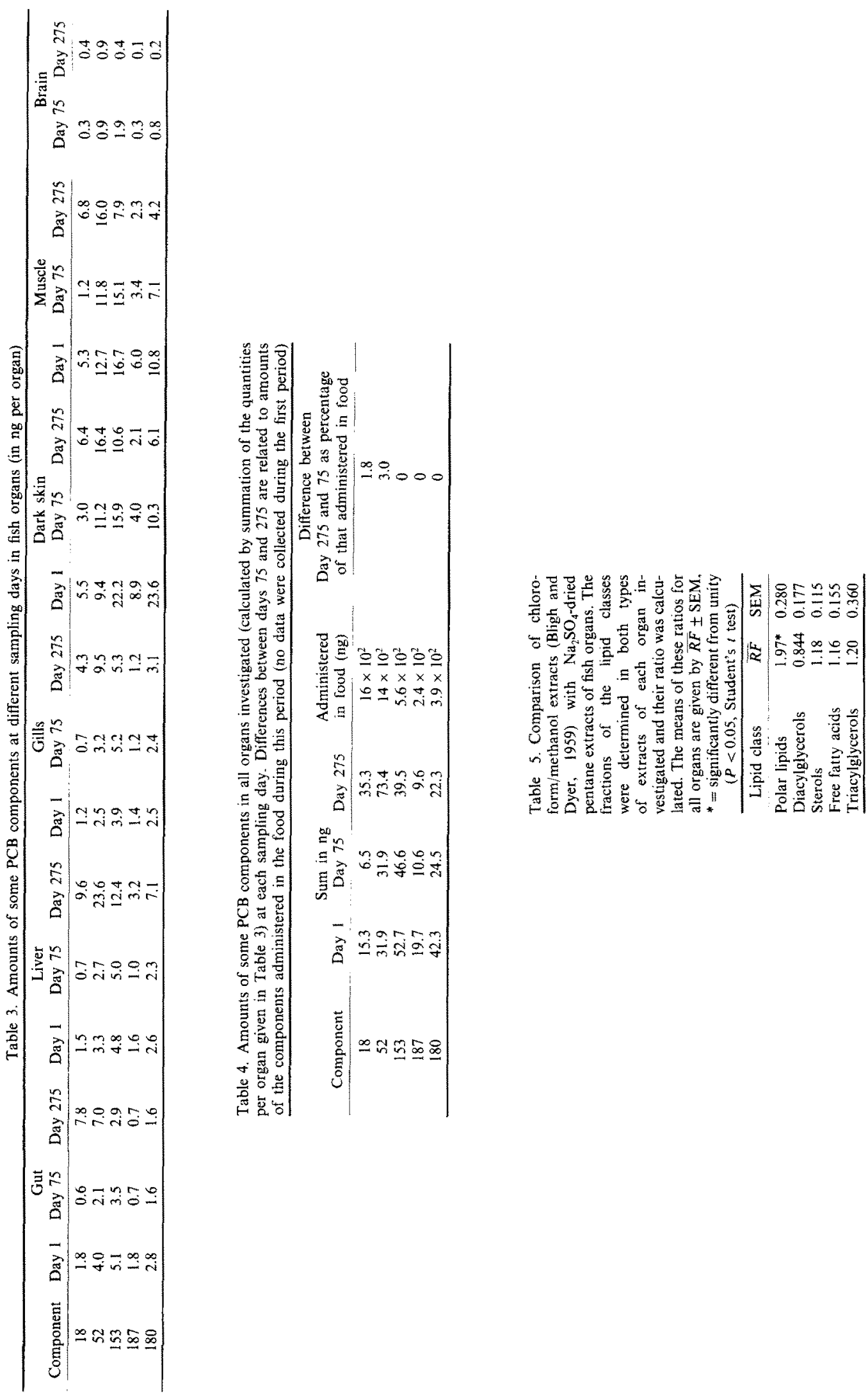


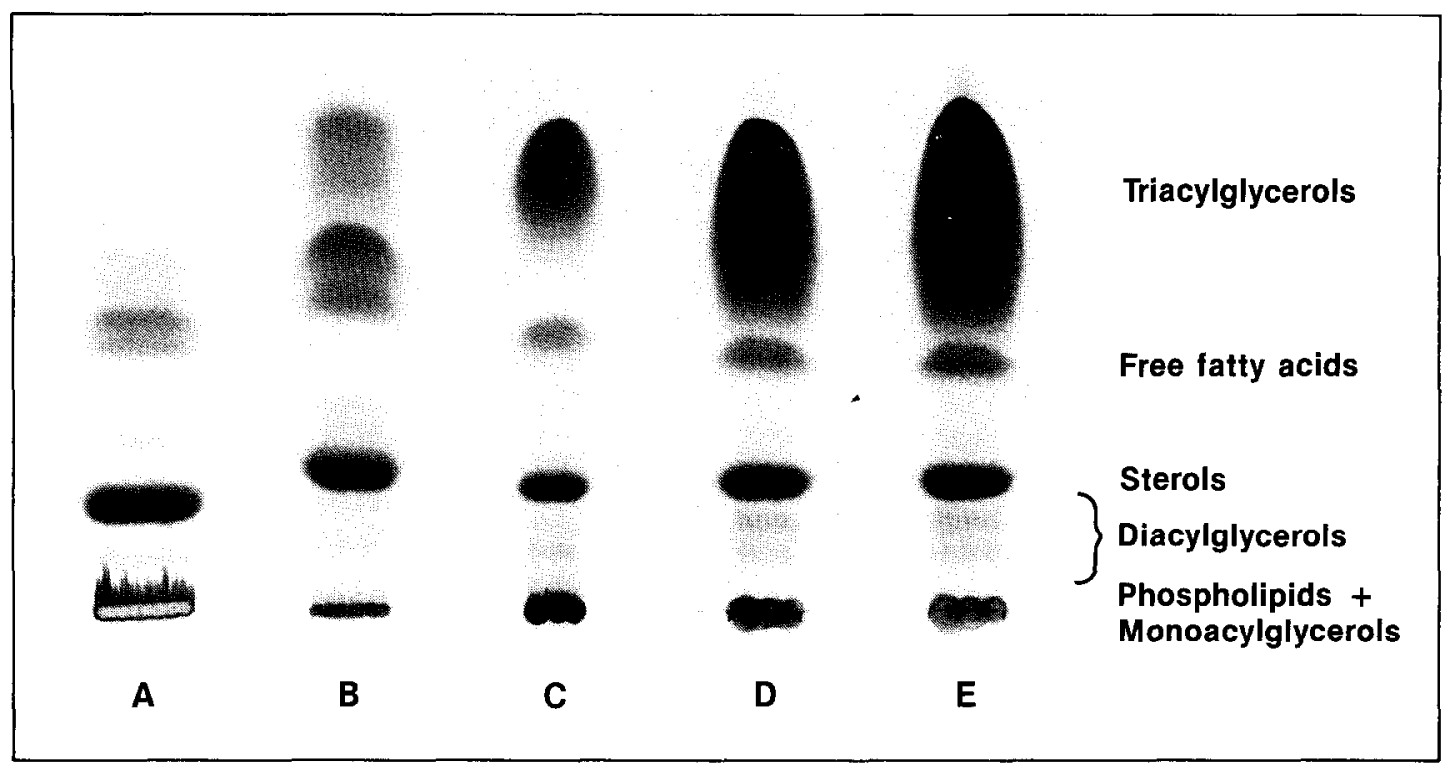

Fig. 8. Comparison of thin-layer chromatograms of lipid extracts of homogenates of dark skin of juvenile Solea solea (a) day 1 (pentane extract); (b) day 75 (pentane extract); (c) day 275 (chloroform/methanol extract); (d) day 275 (pentane extract); (e) duplicate of (d).

GUT
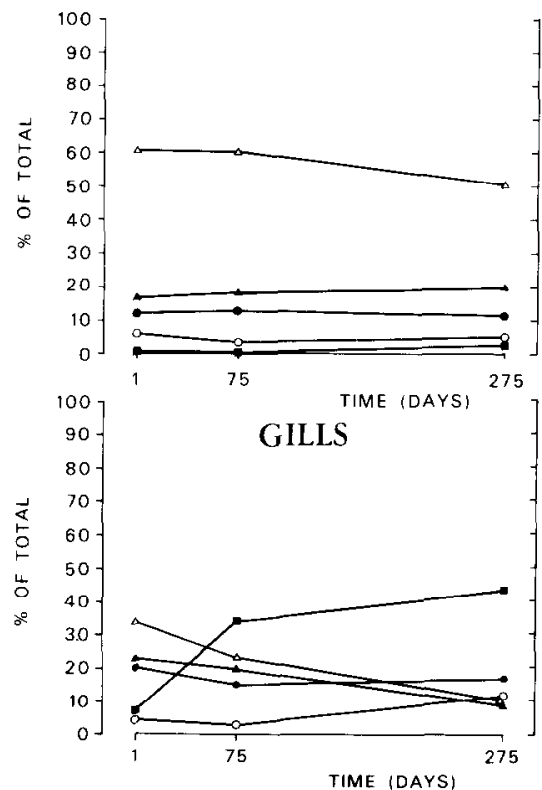

DARK SKIN

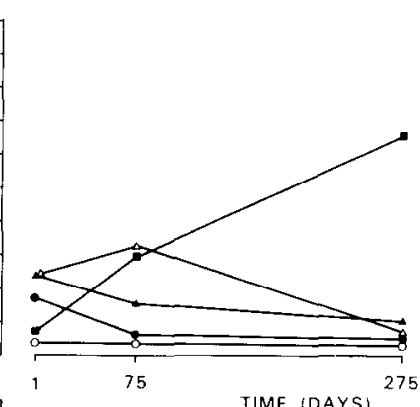

LIVER

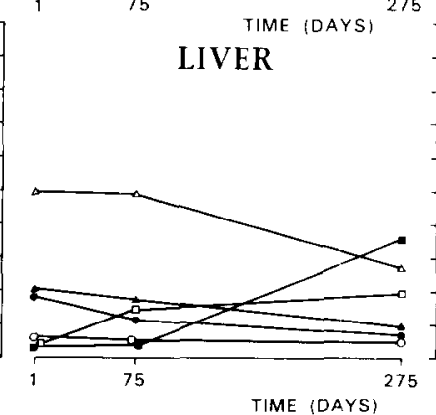

BR A IN

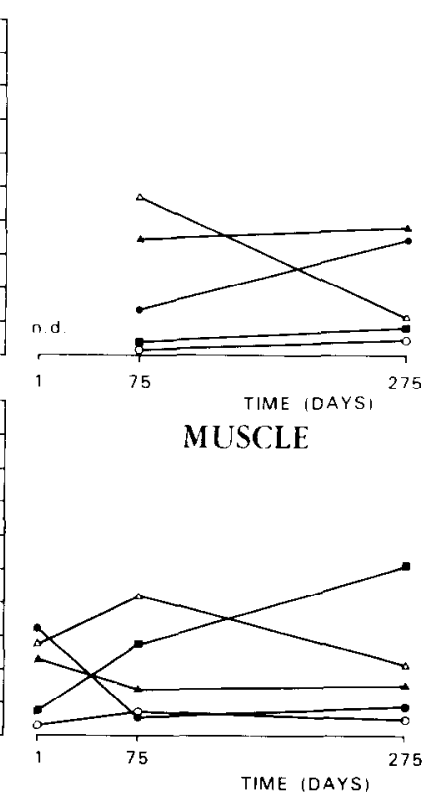

Fig. 9. Fractions (in percentage of total lipids) of different lipid classes present in homogenates of organs of juvenile Solea solea sampled at days 1,75 and 275. = Polar lipids, $O=$ diacyglycerols, $\mathbf{\Delta}=$ sterols, $\Delta=$ free fatty acids, $\square=$ triacylglycerols, $\square=$ sterylesters (only present in liver). n.d. = no data. 


\section{REFERENCES}

Allen W. V. (1976) Biochemical aspects of lipid storage and utilization in animals. Am. Zool. 16, 631-647.

Ballschmiter K. and Zell M. (1980) Analysis of polychlorinated biphenyls (PCB's) by glass capillary gaschromatography. Composition of technical Aroclor- and Clophen-PCB mixtures. Z. analyt. Chem. 302, 20-31.

Björkman L. R., Karlsson K. A. and Nilsson K. (1972) On the existence of cerebroside and cholesterol sulfate in tissues of the sea star, Asterias rubens. Comp. Biochem. Physiol. 43B, 409-411.

Bligh E. G. and Dyer W. J. (1959) A rapid method of total lipid extraction and purification. Can. J. Biochem. Physiol. 37, 911-917.

Boon J. P. (1984) Uptake, distribution and elimination of selected polychlorinated biphenyl components of Clophen A40 in juvenile sole (Solea solea) and effects on growth. In Eighteenth European Marine Biology Symposium, Marine Biology of Polar Regions and Effects of Stress on Marine Organisms (Edited by Gray J. S. and Christiansen M. E.). Wiley, Chichester. (In Press).

Bruggeman W. A., Martron L. B. J. M., Kooiman D. and Hutzinger O. (1981) Accumulation and elimination of di-, tri-, and tetrachlorobiphenyls by goldfish after dietary and aqueous exposure. Chemosphere 10, 811-832.

Bruggeman W. A., van der Steen J. and Hutzinger O. (1982) Reversed-phase thin-layer chromatography of polynuclear aromatic hydrocarbons and chlorinated biphenyls. Relationship with hydrophobicity as measured by aqueous solubility and octanol-water partition coefficient. $J$. Chromat. 238, 335-346.

Duinker J. C. and Hillebrand M. T. J. (1983) Characterization of PCB components in Clophen formulations by capillary GC-MS and GC-ECD techniques. Envir. Sci. Technol. 17, 449-456.

Fonds M. (1975) The influence of temperature and salinity on growth of young sole Solea solea L. Tenth Eur. Symp. Mar. Biol., Ostend, Belgium, 17-23 September, Vol. 1, pp. 109-125.

Guiney P. D. and Peterson R. E. (1980) Distribution and elimination of a polychlorinated biphenyl after acute dietary exposure in yellow perch and rainbow trout. Archs Envir. Contam. Toxic. 9, 667-674.

Guiney P. D., Peterson R. E., Melancon M. J. Jr and Lech J. J. (1977) The distribution and elimination of $2,5,2^{\prime}, 5^{\prime}-\left({ }^{14} \mathrm{C}\right)$ tetrachlorobiphenyl in rainbow trout (Salmo gairdneri). Toxic. appl. Pharmac. 39, 329-338.

Guiney P. D., Melancon M. J. Jr, Lech J. J. and Peterson R. E. (1979) Effects of egg and sperm maturation and spawning on the distribution and elimination of polychlorinated biphenyl in rainbow trout (Salmo gairdneri). Toxic. appl. Pharmac. 47, 261-272.

Hansen D. J., Parrish P. R. and Forester J. (1974) Aroclor 1016: Toxicity to and uptake by estuarine animals. Envir. Res. 7, 363-373.

Langston W. J. (1978) Accumulation of polychlorinated biphenyls in the cockle Cerastoderma edule and the tellin Macoma balthica. Mar. Biol. 45, 265-272.

Oudejans R. C. H. M. and van der Sluis I. (1979) Storage and depletion of lipid components in the pyloric cacca and ovaries of the seastar Asterias rubens during its annual reproductive cycle. Mar. Biol. 53, 239-247.

Pizza J. S. and O'Connor J. M. (1983) PCB dynamics in Hudson river striped bass. II. Accumulation from dietary sources. Aquat. Toxic. 3, 313-327.

Schneider R. (1982) Polychlorinated biphenyls (PCB's) in cod tissues from the Western Baltic: Significance of equilibrium partitioning and lipid composition in the bioaccumulation of lipophilic pollutants in gill-breathing animals. Meeresforschung 29, 69-79.

Shaw G. R, and Connell D. W. (1982) Factors influencing concentrations of polychlorinated biphenyls in organisms from an estuarine ecosystem. Aust. J. mar. Freshwat. Res. 33, $1057-1070$.

Tulp M. Th. M. and Hutzinger O. (1978) Some thoughts on aqueous solubilities and partition coefficients of PCB, and the mathematical correlation between bioaccumulation and physico-chemical properties. Chemosphere 10, 849-860.

Yoshida T., Takashima F. and Watanabe T. (1973) Distribution of $\left[{ }^{14} \mathrm{C}\right] \mathrm{PCB}$ in carp. Ambio $2,111-113$. 